УДК: 81.1

ББК 83.3(2Рос)

\section{Э.Г. Манукян}

\section{МИР ДЬЯКОНА ПОБЕДОВА В ПОВЕСТИ А.П. ЧЕХОВА «ДУЭЛЬ": СМЕХ, ДИАЛОГ, ПРОСТРАНСТВО}

Статья посвящена исследованию феномена смеха, который является важной деталью образа дьякона Победова в повести А.П. Чехова «Дуэль». Смех дьякона, как реакция на слова и действия других персонажей, реализуется в диалогах в случаях, когда он является сторонним наблюдателем коммуникативного акта. В таком контексте смех рассматривается как оценка коммуникативного события в целом. Исследование показывает, что дьякон, находясь в пространстве природы, лишается смеха как положительной реакции. В таком пространстве дьякон, с одной стороны, во внутреннем диалоге выступает в роли человека мечтающего и человека размышляющего, а с другой стороны в роли человека, испытывающего чувства, противоположные смеху: страх, отчаяние, волнение.

Ключевые слова: Чехов, повесть «Дуэль», дьякон Победов, смех, диалог, пространство природь.

DOI 10.18522/1995-0640-2020-2-27-35

Манукян Эдгар Георгиевич - аспирант кафедры русского языка Института филологии, журналистики и межкультурной коммуникации Южного федерального университета

Тел.: 8-951-844-36-35

E-mail: edgar.loveme@mail.ru

(C) Манукян Э.Г., 2020.
Повесть «Дуэль», впервые опубликованная в 1891 г. в газете «Новое время», является самым крупным произведением чеховской прозы и считается завершением идейных и художественных исканий писателя середины 80-х начала 90-х гг. Основные проблемы, волновавшие Чехова в тот период, вошли в сложное идейнохудожественное единство повести. Главным предметом исследований в этой повести для ученых-чеховедов (и не только) является образ Лаевского и его взаимоотношения с другими героями повести. Однако для раскрытия идейно-художественного своеобразия произведения необходимо рассмотрение всех персонажей, один из которых - дьякон Победов. Данное исследование посвящено изучению феномена смеха, который служит главным и важным маркером образа дьякона. Смех дьякона в повести - это не просто деталь, а целое понятие, выражающее чеховскую оценку действительности.

В.В. Розанов, исследуя гоголевское «комическое», затрагивал такой феномен, как дух христианства. Как отмечал ученый, для православной христианской традиции, в аспекте ее аскетики, смех и различные его проявления если и не запрещены напрямую, то чужды и осуждаемы [Толковый словарь..., с. 86]. Синиша Елушич вслед за другими исследователями говорит о возможности двоякого понимания понятия «смех» в христианской традиции: во-первых, это смех как таковой, греховный по своей сути, и, во-вторых, это духовный смех, не соотносимый с греховностью [Елушич, 2014, 
с. 55]. Архиепископ Иоанн Шаховской, размышляя о смехе и религии, выделяет два типа смеха: светлый и темный. По мысли Иоанна Шаховского, проявление того и другого типа зависит от проявления физических характеристик лица, т. е. эти оппозиции находятся в зависимости от физиса человека. Светлый, благодатный смех свидетельствует о том, что человек обрел душевную гармонию. Темный смех, в свою очередь, показывает, что душа человека изменена в отрицательную сторону, а это выражается в деформации черт его лица, главным образом, в «кривлении» [Архиепископ Иоанн Шаховской, 2009, с. 25]. В описании и в ремарках к репликам, характеризующих дьякона Победова, смех играет важную роль в понимании этого персонажа и функций, которые Победов выполняет в повести. Отдельные фрагменты текста дают возможность проанализировать источник смеха дьякона:

«Дьякон был очень смешлив и смеялся от каждого пустяка до колотья в боку, до упада. Казалось, что он любил бывать среди людей только потому, что у них есть смешные стороны и что им можно давать смешные прозвища» (VII, с. 373).

Такие маркеры смеха, как «до колотья в боку», «до упада» не могут выражать собой душевную гармонию. Устойчивое выражение «до колотья в боку» означает «до полной потери сил, до изнеможения», $\mathrm{a}$ «до упада» - «до полного изнеможения (делать что-либо)» [Федоров, 2008 , с. 76]. Очевидно, что такой смех подразумевает некоторые изменения черт лица, т. е. мимические признаки смеха. Мимика лица дьякона штриховым описанием дается в следующем фрагменте текста:

«Он жадно всматривался в лища, слушал не мигая, и видно было, как глаза его наполнялись смехом и как напрягалось лищо в ожидании, когда можно будет дать себе волю и покатиться со смеху» (VII, с. 373).

В данном случае Чехов дает более детализированный портрет дьякона. Всматривался «жадно», слушал «не мигая» - маркеры, служащие усилению степени действия. В данном случае их можно рассматривать как признак так называемой одержимости: глаза «наполнились смехом», а лицо «напряглось». Такая градация в мимике ведет к конечному результату: «дать себе волю», чтобы «покатиться со смеху». В другой главе дьякон дал себе волю и «покатился там со смеху» от диалога доктора Самойленко с зоологом фон Кореном:

«Дьякон, никогда не видавший доктора таким величественным, надутым, багровым и страшным, зажал рот, выбежал в переднюю и покатился там со смеху» (VII, с. 387).

В данной описанной ситуации при изображении смеха дьякона Чехов использует фразеологическое сочетание: «покатиться со смеху» «громко, безудержно смеяться, хохотать» [Быстрова, Окунева, Шанский, 1984, с. 215]. Как уже было отмечено, Чехов использует и другие фразеологические выражения: «смеяться до упаду», «смеяться до колотья в боку». Отсюда, скорее всего, - это темный смех. Святитель Иоанн Златоуст писал: «Не смех - зло, но зло то, когда он бывает без меры, когда он неуместен. Способность смеха внедрена в нашу душу для того, 
чтобы душа иногда получала облегчение, а не для того, чтобы расслаблялась» [Православная энциклопедия..., т. 12, ч. 1, беседа 15]. Получается, что смех сам по себе не является грехом, но может нести в себе греховность, если им пренебрегать. В целом же смех является средством облегчения, достижения гармонии и понимания. Получается, что дьякон обладает греховным смехом, так как смеялся «от каждого пустяка».

Так, смех дьякона является отражением его внутреннего состояния и показывает обратную сторону его «сана» - греховную. Однако помимо этой функции смех как деталь поведения дьякона выполняет еще одну функцию, которая раскрывает общую концепцию повести. Здесь необходимо указать и на иное видение смеха. Протопресвитер Александр Шмеман пишет, что смех имеет смысл рассматривать как феномен, «исполненный святости и благодарности к Богу за дарованное счастье», а человеку нужно, «смеясь, к нему воспарять». Богослов Шмеман рассматривает смех как молитву и отмечает, «что смех в религиозном значении потерялся и не звучит уже в мире... Да, смех - любовь, смех - благодарность... Пошлость же по-настоящему обличается, разится только смехом» [Протопресвитер Александр Шмеман, 2005, с. 475].

Диалогическое общение в повести, субъектом которого является дьякон, можно разделить на два типа: внецерковный религиозно-философский дискурс и бытовой дискурс (с разнообразной тематикой - любви, социального положения человека, развлечения и др.). Если противопоставлять дьякона Победова остальным героям повести, то становится понятным идейное содержание некоторых фрагментов текста, где одним из субъектов в бытовом дискурсе является сам дьякон: он в какой-то степени является третейским судьей в диалогах героев, а его вердикт это смех.

«-Для Лаевского я не могу дать. Я знаю, ты любишь давать взаймы. Ты дал бы и разбойнику Кериму, если бы он попросил у тебя, но, извини, помогать тебе в этом направлении я не могу.

- Да, я прошу для Лаевского! - сказал Самойленко, вставая и размахивая правой рукой. - Да! Для Лаевского! <... .

Дьякон захохотал» (VII, с. 408).

В аспекте содержания диалога смех дьякона вызван эмоциональным отношением, рефлексивным психологическим действием на фразы и жесты Самойленко в данном диалоге. Смех может вызвать и случайно сказанное слово либо гротескное сравнение:

«Телом он вял, хил и стар, а интеллектом ничем не отличается от толстой купчихи, которая только жрет, пьет, спит на перине и держит в любовниках своего кучера.

Дьякон захохотал» (VII, с. 373).

В диалогических ситуациях фон Корена и доктора Самойленко дьякон зачастую не участвует как субъект говорящий, однако находится в этом пространстве физически и является слушателем. Здесь смех (в широком понимании) - это некий штрих, который заключает в себе отношение третьего человека в споре двух, то есть - взгляд со сторо- 
ны. В этом аспекте проявляется социальная функция смеха. По мнению Д.М. Гайнуллиной, смех помогает человеку «вписаться в коллектив, примирить его с непредсказуемостью и серьезностью жизни в целом» [Гайнуллина, 2013, с. 35]. Споры, которые ведут между собой герои в данных диалогах, относящиеся исключительно к бытовой сфере, так называемой суете, не имеют какой-либо целевой установки, однако они важны в понимании отношений между героями, особенно между Лаевским и фон Кореном. Так, глагол «захохотать», использованный в ремарках, в словаре В.И. Даля означает «начать хохотать, засмеяться вслух», a «хохотать» - «громко смеяться, заливаться смехом или гоготать» [Толковый словарь..., http]: т. е. это крайняя степень смеха. Таким образом, получается, что дьякон своим смехом обличает всю пустоту и ненужность данного диалогического спора: дьякон «захохотал», потому что он смеялся «от каждого пустяка». Дьякона доводят до такой степени смеха не только «смешные» слова, а в целом то, что связано с отношениями двух вышеуказанных персонажей. Победов выступает в данном случае сторонним наблюдателем. Это доказывает мысль А.Г. Козинцева о том, что смех может содействовать становлению критической личности, которая «способна ощущать себя автономно в системе социального взаимодействия» [Козинцев, 2007, с. 42]. По мнению А.Г. Козинцева, смех помогает «соблюдать дистанцию по отношению к окружающей действительности, вырабатывать оценку происходящего, проявлять инициативу в выработке норм и усовершенствовании традиций» [Там же].

Смех маркирует речь дьякона в диалоге с религиозно-философской тематикой - разговор с фон Кореном о вере. В этом случае смех характеризуется снисходительной интонацией, а речь может сопровождаться тактильным жестом:

«Дьякон засмеялся и похлопал зоолога по плечу» (VII, с. 433).

В этом же диалоге возникает оппозиция смеху, которая выражается в ремарке в виде распространителя глагола говорения - наречия «горячо» (негативном эмоциональном выражении):

«- Значит, любовъ в том, чтобы сильный побеждал слабого?

- Несомненно.

- Но ведь сильные распяли господа нашего Иисуса Христа! - сказал горячо дьякон» (VII, с. 431).

Образ дьякона Победова совсем неоднозначен и в какой-то мере даже противоречив. Можно говорить о том, что образ Победова и его мир раскрываются Чеховым косвенно в межличностном общении с остальными персонажами, а более подробно и точно - во внутренних диалогах в пространстве природы. Природное пространство либо сопутствует размышлениям дьякона, репрезентирует его внутреннюю речь, либо является само по себе самодостаточным элементом в собирательной мозаике повести. Природа - то пространство, где раскрываются эстетические взгляды дьякона:

«Дьякон пошел за рыбой, которую на берегу чистил и мыл Кербалай, но на полдороге остановился и посмотрел вокруг. - Боже мой, как хоро- 
шо! - подумал он. - Люди, камни, огонь, сумерки, уродливое дерево - ничего больше, но как хорошо!» (VII, с. 388).

Кроме эстетических взглядов пространство природы помогает раскрыть читателю и мечты дьякона, его цели и ожидания. Находясь в окружении других людей (персонажей повести) в пространстве природы, дьякон мечтает:

«Слушая их, дьякон вообразил, что будет с ним через десять лет, когда он вернется из экспедищи: он - молодой иеромонах-миссионер, автор с именем и великолепным прошльм; его посвящают в архимандриты, потом в архиереи; он служит в кафедральном соборе обедню; в золотой митре, с панагией выходит на амвон и, осеняя массу народа трикирием и дикирием, возглашает <... > (VII, с. 389).

В повести дьякон не помещен Чеховым в церковное пространство. Однако сам дьякон, находясь в пространстве природы, воображает себя священнослужителем, причем в его мечтах показывается динамика жизни, постепенное повышение сана, изображается служба.

Природа может соотноситься с настроением дьякона: природные реалии отвечают его эмоциональному состоянию.

«От дождя речка стала шире и злее, и уж она не ворчала, как прежде, а ревела. Начинался рассвет. Серое тусклое утро, и облака, бежавшие на запад, чтобы догнать грозовую тучу, и горы, опоясанные туманом, и мокрые деревья - всё показалось дьякону некрасивым и сердитым $<\ldots>$ Вспомнилась ему дьяконица и «Невозвратное», которое она играет на фортепиано. Что она за женщина? Дьякона познакомили, сосватали и женили на ней в одну неделю; пожил он с нею меньше месяца и его командировали сюда, так что он и не разобрал до сих пор, что она за человек. А все-таки без нее скучновато» (VII, с. 441).

Данный фрагмент показывает, что дьякон Победов, находясь в пространстве природы, способен к рефлексии, к анализу собственной жизни. Серое утро метафорически соотносится со скукой, которую испытывает дьякон. В этом же фрагменте дьякон размышляет и над вопросами нравственного характера: долг, справедливость, грех. В этой ситуации главными маркерами поведения дьякона становятся глаголы «успокаивал» и наречие «жутко»:

«Дьякону стало жутко. Он подумал о том, как бы бог не наказал за то, что он водит компанию с неверующими и даже идет смотреть на их дуэль. <...> Они хотя неверующие, но добрые люди и спасутся», - успокаивал он себя. - Обязательно спасутся! - сказал он вслух, закуривая папиросу. Какою мерою нужно измерять достоинства людей, чтобы судить о них справедливо?» (VII, с. 440).

Пространство природы является местом и для нравственно-этических размышлений дьякона:

«Если бы они с детства знали такую нужду, как дьякон, если бы они воспитывались в среде невежественных, черствых сердием, алчных до наживы, попрекающих куском хлеба, грубых и неотесанных в обращении, плюющих на пол и отрыгивающих за обедом и во время молитвы, если бы 
они с детства не были избалованы хорошей обстановкой жизни и избранным кругом людей, то как бы они ухватились друг за друга, как бы охотно прощали взаимно недостатки и ценили бы то, что есть в каждом из них. Ведь даже внешне порядочных людей так мало на свете!» (VII, с. 441).

Отсюда следует, что в пространстве природы дьякон лишается своей главной черты - смеха. Значит, смех как таковой может быть не присущ дьякону, а выработан им, реализован в окружении живых людей. Находясь в одиночестве, дьякон не смеется, но думает о смехе:

«Дьякон стал решать этот вопрос, но ему вспомнилось, какая смешная фигура была сегодня у Самойленка, и это прервало течение его мыслей. Сколько завтра будет смеху! Дьякон воображал, как он засядет под куст и будет подсматривать, а когда завтра за обедом фон Корен начнет хвастать, то он, дьякон, со смехом станет рассказывать ему все подробности дуэли» (VII, с. 440).

Дуэль, которая состоялась (точнее - не состоялась) в пространстве природы, помогает посмотреть на образ Победова с другой стороны. В этом случае раскрываются совершенно другие эмоции и состояния дьякона: страх и сопутствующее ему отчаяние:

«-Он убьет его! - посльпиался вдруг отчаянный крик где-то очень близко» (VII, с. 448).

Следует рассмотреть один из важнейших сюжетообразующих фрагментов повести, в котором в большом объеме представлен спектр эмоций дьякона:

«Немного погодя фон Корен и дьякон сошлись около мостика. Дьякон был взволнован, тяжело дышал и избегал смотреть в глаза. Ему было стьдно и за свой страх, и за свою грязную, мокрую одёжу.

- Мне показалось, что вы хотели его убить... - бормотал он. - Как это противно природе человеческой! До какой степени это противоестественно!

- Как вы сюда попали, однако? - спросил зоолог.

- Не спрашивайте! - махнул рукой дъякон. - Нечистьй попутал: иди да иди... Вот и пошел, и чуть в кукурузе не помер от страха. Но теперь, слава богу, слава богу... Я весьма вами доволен, - бормотал дъякон. - И наш дедка-тарантул будет доволен... Смеху-то, смеху! А только я прошу вас убедительно, никому не говорите, что я был тут, а то мне, пожалуй, влетит в загривок от начальства. Скажут: дьякон секундантом был» (VII, с. 448).

Здесь Чехов, описывая эмоциональное состояние дьякона, изображает его человеком, который находится в ситуации, противоположной комической. Теперь он находится в состоянии волнения, на которое указывает составное именное сказуемое «был взволнован»; чувствует стыд, на который указывает составное именное сказуемое «ему было стыдно»; в состоянии страха, на который указывает фразеологическое сочетание «чуть [в кукурузе] не помер от страха». В такой ситуации дьякон не «жадно всматривался в лица», когда он давал волю смеху, а «избегал смотреть в глаза», не смеялся, а «тяжело дышал». Так, дьякон из субъек- 
та, который потешался над поступками и действиями людей, погрязших в абсурдности жизни, сам превратился в объект жизненных перипетий. Страх берет верх над смехом, однако дьякон вновь возвращается к пониманию того, что без смеха ему не обойтись и в данной драматической ситуации, и он обыгрывает ситуацию, размышляя о том, что потом скажут о нем самом и об этой ситуации в целом: «смехy-mo, cмexy!». В этой фразе дьякона кроется компенсаторная функция смеха. Как пишет Д.М. Гайнуллина, смех выполняет эту роль, «противопоставляясь страху и серьезности обыденной жизни и сублимируя асоциальные желания» [Гайнуллина, 2013, с. 36]. Именно поэтому смех, по М.П. Громову, - это «родная стихия Чехова, противостоящая робости, болезненной скованности, страху» [Громов, 1989, с. 149].

Таким образом, дьякон предстает в двух статусах: в одной он - сторонний наблюдатель, осмеивающий и тем самым дающий оценку происходящему; в другой - человек, выражающий чувства и мысли.

Особенно наглядно противопоставление смеха и противоположных ему значений выражено в сопоставлениях дьякона с другими персонажами повести, характеризующимися негативными описаниями, обозначающими, главным образом, грусть (печаль, тоску) и ненависть (вражду, злобу). Следовательно, смех - это не только характерная черта образа дьякона, но и некий индикатор, с помощью которого Чехов выражает контраст, усиливающий трагическое осмысление повести «Дуэль» и судеб ее героев. Поэтому смех дьякона является своего рода оценкой всех ссор и конфликтов персонажей, приводящих к драматическим последствиям.

Смех в повести Чехова - это некая защитная реакция, способ увидеть и преодолеть абсурдность, несуразность жизни, хаос, творящийся в мире, страхи, присущие человеку. Если следовать мнению Critchley, то такое явление, как смех, «происходит от понимания, что существует только этот мир, и сколь бы он ни был несовершенен, единственное, что нам доступно, так это смеяться» [Critchley, 2014, p. 27]. По всей видимости, по этой причине дьякон Победов в коммуникации с другими персонажами осознанно или нет старается сводить жизненные ситуации к смеху.

Таким образом, смех для Чехова - это далеко не всегда высмеивание чего-нибудь или кого-нибудь. Чеховская категория смеха воплощала «стремление к веселости, радости, свойственное всему живому - или, по крайней мере, всему, что в нас остается живым» [Громов, 1989, с. 281]. Возможно, Чехов реализовал данную концепцию в этом представителе духовенства в повести, а возможно, это его действительное отношение к современному ему поколению конца XIX - начала XX в., которое было не в состоянии справляться с социальными потрясениями и изменениями и преодолевало это бремя в том числе с помощью смеха.

\section{Литература}

Архиепископ Иоанн Шаховской. Апокалипсис мелкого греха. Избранные статьи. М.: Изд-во Сретенского монастыря, 2009. 224 с.

Быстрова Е.А., Окунева А.П., Шанский Н.М. Учебный фразеологический словарь русского языка. Л.: Просвещение, 1984. 271 с. 
Гайнуллина Д.М. Смех как физиологическая, социальная и лингвистическая составляющая нашей жизни // Вестн. ЧГУ, 2013. № 35. С. 34-39.

Громов М.П. Книга о Чехове. М.: Современник, 1989. 384 с.

Елушич, Синиша. Христианство и смех: спор вокруг гоголевского понимания комического // Вестн. славянских культур. М., 2014. № 4 (34). С 53-69.

Козинщев А.Г. Смех, плач, зевота: психология чувств или этология общения? [Электронный ресурс]. СПб, 2007. - URL: http://ethology.ru/library/?id=271 (дата обращения 27.10.2019).

Православная энциклопедия «Азбука веры» [Электронный ресурс]. URL: https://azbyka.ru/smex (дата обращения 13.12.2019).

Протопресвитер Александр Шмеман. Дневники. 1973-1983. М.: Русский путь, 2005. 720 с.

Розанов В. В. О Сладчайшем Иисусе и горьких плодах мира. В темных религиозных лучах. Темный лик // Собр. соч. под общ. ред. А.Н. Николюкина. М.: Республика, 1994. 476 с.

Толковый словарь живого великорусского языка В.И. Даля [Электронный pecypc]. - URL: http://slovardalja.net (дата обращения 17.01.2019).

Федоров А.И. Фразеологический словарь русского литературного языка. М.: АСТ, Астрель, 2008. 878 с.

Чехов А.П. Полн. собр. соч. и писем: в 30 т. М.: Наука, 1977. Т. 7. С. 353-455.

Critchley, Simon. On humour. London and New York: Routledge, 2004. 132 p.

\section{References}

Arkhiepiskop Ioann Shakhovskoi. Apokalipsis melkogo grekha. Izbrannye stat’i. Moskow, Izdatel'stvo Sretenskogo monastyrya, 2009. 224 p. (In Russian).

Bystrova E.A., Okuneva A.P., Shanskii N.M. Uchebnyi frazeologicheskii slovar' russkogo yazyka. Leningrad, Prosveshchenie, 1984. $271 \mathrm{p}$.

Chekhov, A.P. Polnoe sobranie sochinenii i pisem: v 30 tomakh. Moskow, Nauka, 1977. Vol. 7, pp. 353-455. (In Russian).

Critchley, Simon. On humour. London and New York, Routledge, 2004. 132 p. (In Russian).

Elushich, Sinisha. Khristianstvo i smekh: spor vokrug gogolevskogo ponimaniya komicheskogo. Vestn. slavyanskikh kul'tur. Moskow, 2014, no. 4 (34), pp. 53-69. (In Russian).

Fedorov A.I. Frazeologicheskii slovar' russkogo literaturnogo yazyka. Moskow: AST, Astrel', 2008.878 p. (In Russian).

Gainullina, D.M. Smekh kak fiziologicheskaya, sotsial'naya i lingvisticheskaya sostavlyayushchaya nashei zhizni. Vestn. ChGU, 2013, no. 35, pp. 34-39. (In Russian).

Gromov, M.P. Kniga o Chekhove. Moskow, Sovremennik, 1989. 384 p.

Kozintsev, A.G. Smekh, plach, zevota: psikhologiya chuvsto ili etologiya obshcheniya? [Elektronnyi resurs]. SPb, 2007. - URL: http://ethology.ru/ library/?id=271 (accessed 27.10.2019). (In Russian).

Pravoslavnaya entsiklopediya «Azbuka very» [Elektronnyi resurs]. - URL: https://azbyka.ru/smex (accessed 13.12.2019). (In Russian).

Protopresviter Aleksandr Shmeman. Dnevniki. 1973-1983. Moskow: Russkii put', 2005. 720 p. (In Russian).

Rozanov, V. V. O Sladchaishem Iisuse i gor'kikh plodakh mira. V temnykh religioznykh luchakh. Temnyi lik. Sobranie sochinenii pod obshch. red. A.N. Nikolyukina. Moskva, Respublika, 1994. 476 p. (In Russian). 
Tolkovyi slovar' zhivogo velikorusskogo yazyka V.I. Dalya [Elektronnyi resurs]. - URL: http://slovardalja.net (accessed 17.01.2019). (In Russian).

Edgar G. Manukyan (Rostov-on-Don, Russian Federation) World of Deacon Pobedov in Chekhov's Novel «The Duel»: Laughter, Dialogue, Space

This article deals with the study of the phenomenon of laughter, which is an important component and feature of the character of deacon Pobedov in Chekhov's novel «The Duel». The deacon's laughter, as a reaction to the words and actions of other characters, implements in dialogues when Pobedov acts as an observer of the act of communication. In this context, laughter should be considered as an assessment of a communicative event. The study shows that the deacon, being in the space of nature, loses laughter as a positive reaction. In this space, the deacon, on the one hand, in the internal dialogue acts as a dreaming and reflecting person, and, on the other hand, a person experiencing feelings of fear, despair, and excitement.

Key words: Chekhov, «The Duel», deacon Pobedov, laughter, dialogue, space of nature.

Edgar G. Manukyan - a post-graduate student of the department of Russian language of the Institute of Philology, Journalism and Cross-Cultural Communication of the Southern Federal University. Phone.: +7-951-844-36-35, e-mail: edgar.loveme@mail.ru 